\title{
SUJEITOS SOCIAIS COLETIVOS E A POLÍTICA DE FORMAÇÃO INICIAL E CONTINUADA EMERGENCIAL DE PROFESSORES: CONTRADIÇÕES VS CONCILIAÇÕES
}

IRIA BRZEZINSKI*

RESUMO: Neste artigo, realizam-se análises conceituais e de açôes do Fórum Permanente de Apoio à Formação Docente (Forprof) como articulador e regulador dos Planos Estratégicos de Formação Inicial e Continuada de Professores em exercício nos sistemas públicos de ensino. $\mathrm{O}$ artigo consiste em recorte de uma pesquisa qualitativa, de abrangência nacional, com utilização da pesquisa participante. Almeja-se perquirir os impactos da implementação do Plano Nacional de Formaçáo de Professores (Parfor), fomentado pela Capes da Educação Básica (Capes/EB) e, ainda, as relaçóes conflitantes ou conciliatórias estabelecidas nesse espaço plural e democrático - o Forprof.

Palavras-chave: Políticas de Formação de Professores. Fóruns Permanentes de Apoio à Formação Docente. Sujeitos Sociais Coletivos.

\section{COLLECTIVE SOCIAL SUBJECTS AND INITIAL, PERMANENT AND EMERGENCIAL TEACHER FORMATION POLICIES: CONTRADICTIONS VS CONCILIATIONS}

ABSTRACT: This article analyses the conceptual framework and the actions of the Permanent Forum for Teacher Education Support (Forprof), as it coordinates and regulates the Strategic Plans for the Initial and Continuing Education of teachers who work in public education systems. The article presents part of the findings of a nationwide qualitative research which used participatory research. It aims to investigate the impacts of the implementation of the National Plan for Teacher Education (Parfor), supported by Basic Education Capes, as well as the conflicting or conciliatory relations established in that plural and democratic space - the Forprof.

Keywords: Teacher Education Policies. Permanent Forums for Teacher Education Support. Collective Social Subjects.

* Pontifícia Universidade Católica de Goiás, Escola de Professores e Humanidades, Programa de Pós-Graduação em Educação, Goiânia, Goiás, Brasil. E-mail de contato: iriaucg@yahoo.com.br 


\title{
DES SUJETS SOCIAUX COLLETIFS ET LA POLITIQUE DE FORMATION INITIALE ET CONTINUE ET EMERGENTIELLE D'ENSEIGNANTS: CONTRADICTIONS VS CONCILIATIONS
}

\begin{abstract}
RESUME: Dans cet article, on réalise des analyses conceptuelles et d'actions du Forum Permanent d'Aide à la Formation des Enseignants (Forprof) comme articulateur et regulateur des Plans Stratégiques de Formation Initiale et Continue d'Enseignant en Exercice dans les systèmes publics d'enseignement. L'article consiste à un decoupage d'une recherche qualitative, au niveau national, avec l'utilisation de la recherche participative. Il se convoite étudier les impacts de l'implementation du Plan National de Formation des Enseignants (Parfor), fomenté par la Capes de L'éducation Basique et encore, les rélations conflitantes ou conciliantes établies dans cet espace pluriel et démocratique - le Forprof.
\end{abstract}

Mots-clés: Politiques de Formation Enseignant. Forum Permanents d'Aide à la Formation des Enseignants. Sujets Sociaux Collectifs.

Democracia é sinônimo de soberania popular. Podemos defini-la como presença efetiva das condiçóes sociais e institucionais que possibilitam ao conjunto de cidadãos a participação ativa na formação do governo e, em consequência no controle da vida social. [...] Cidadania é a capacidade conquistada por alguns indivíduos, ou (no caso de uma democracia efetiva) por todos os indivíduos, de se apropriarem dos bens socialmente criados, de atualizarem todas as potencialidades de realização humana abertas pela vida social em cada contexto historicamente determinado. (COUTINHO, 2008, p. 50) (grifos do autor).

\section{Considerações iniciais}

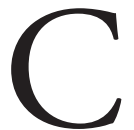

oncorda-se com as ideias em epígrafe sobre os significados de democracia e de cidadania. São conquistas de "[...] condiçóes sociais e institucionais que possibilitam ao conjunto de cidadãos" (COUTINHO, 2008, p. 50) e aos sujeitos sociais coletivos, dentre outros, serem protagonistas ${ }^{1}$ nos governos, na gestão das políticas públicas, no controle social e na apropriação "dos bens socialmente criados".

No momento histórico contemporâneo do Brasil, a interlocução com os cidadáos da sociedade civil e com os sujeitos sociais coletivos como protagonistas, deve ser feita pelo Estado republicano democrático. E a participação social desses sujeitos nas esferas públicas mediante, por exemplo, fóruns, conselhos, comitês de 
governança "[...] se faz para democratizar a gestão da coisa pública, para inverter as prioridades das administrações no sentido de políticas que atendam não apenas as questôes emergenciais”. (GOHN, 2004, p. 20)

Na definição e desenvolvimento das políticas de formação de profissionais da educação, constata-se, contudo, que o governo nas duas últimas décadas opta por práticas de políticas pontuais e emergenciais, por meio de planos e programas dispersos, marcados pela inorganicidade e desarticulação do próprio Ministério da Educação (MEC). No âmbito dessas políticas, ignora-se a importância de um controle social sistemático, o que implica malversação de recursos públicos. Na verdade, não existe uma política pública global de formação e valorização dos profissionais da educação, de modo que se articule a qualidade social dos processos formativos com condiçóes dignas de trabalho, carreira e planos de cargos e salários com base no piso salarial nacional.

Como exemplo de prática política pontual cita-se o Parfor, fomentado e regulado pela Capes/Educação Básica (EB), um plano emergencial para formar professores em serviço. Abrange pessoas atuantes na educação básica pública, porém sem a qualificação exigida pelos dispositivos legais que regulamentam a formação inicial, continuada e a admissão de professores.

Neste artigo, busca-se investigar a importância dos Fóruns Permanentes de Apoio à Formação Docente, também nominados de Fóruns Estaduais e Distrital de Formação de Professores (Forprof/Fepad), criados por meio do Decreto n. 6.755, de 29/1/2009. Esse Decreto instituiu a Política Nacional de Formação de Profissionais do Magistério da Educação Básica e disciplinou a atuação da Coordenação de Aperfeiçoamento de Pessoal de Nível Superior (Capes). Segundo o Decreto, tais fóruns devem constituir espaços de elaboração de políticas e planos estratégicos de formação de professores nos Estados e no Distrito Federal (DF). São integrados por sujeitos sociais coletivos, representantes da sociedade política, das instituições formadoras de profissionais da educação, dos órgãos que regulam os cursos, entre outros.

O presente artigo foi construído com base nos resultados parciais de uma pesquisa de abrangência nacional, financiada pelo Conselho Nacional de Desenvolvimento Científico e Tecnológico (CNPq) e intitulada Observatório da formação e valorização docente: configuraçóes e impactos da implementação dos Fóruns Permanentes de Apoio à Formação do Magistério. A primeira etapa da investigação, objeto deste artigo, foi desenvolvida pelo Núcleo de Pesquisa da Associação Nacional pela Formação dos Profissionais da Educação (Nupanfope), coordenado pela autora deste trabalho.

Iniciada em 2010, a pesquisa se efetivou graças à dedicação dos pesquisadores aos compromissos assumidos com a Associação Nacional pela Formação de Profissionais da Educação (Anfope), pelos representantes das Comissóes Estaduais 
da Entidade e membros titulares nos Forprof. A segunda etapa está em andamento e abrange 2013, marco temporal de atuação dos licenciados egressos dos cursos emergenciais do Parfor.

Esclarece-se que, neste artigo, consideram-se sujeitos sociais coletivos do campo educacional algumas entidades nacionais integrantes do Fórum Nacional em Defesa da Escola Pública (FNDEP), espaço construído por entidades organizadas da sociedade civil, destinado a promover debates, açóes e formular propostas para a educação nacional.

A esse fórum incorporaram-se, entre outras, entidades científicas e sindicais da educação. Tais entidades comungam princípios e desenvolvem ações conjuntas, mantendo uma organização em rede. São elas: Anfope; Associação Nacional de Pós-graduação e Pesquisa em Educação (Anped); Associação Nacional de Políticas e Administração da Educação (Anpae); Centro de Estudos Educação e Sociedade (Cedes); Fórum Nacional de Diretores de Faculdades, Centros de Educação ou equivalentes das Universidades Públicas Brasileiras (Forumdir) e Confederação Nacional dos Trabalhores em Educação (CNTE).

O FNDEP se originou no contexto das Conferências Brasileiras da Educação (CBE), realizadas na década de 1980, com vistas à construção de um projeto para a educação pública nacional. Nos anos 1990, o FNDEF intensificou suas açôes, mobilizando os educadores para a aprovação da nova Lei de Diretrizes e Bases da Educação Nacional, que tramitava no Congresso. Aprovada a LDB, em 1996, houve certo refluxo deste fórum, mas nos anos 2000, suas açóes foram reavivadas com a reedição de sua Declaração de Princípios, segundo a qual esse fórum

[...] constitui-se em uma articulação de entidades e movimentos sociais organizados da sociedade brasileira, com representação nacional, que partilhando princípios, valores, concepçóes e ideais, buscam defender, de forma autônoma e independente, a educação pública, estatal, gratuita, democrática, laica e de qualidade social, para todos os cidadãos e cidadãs brasileiros(as). (FNDEF, 2011, p.1)

Das entidades mencionadas, a Anfope e o CNTE, em virtude de sua natureza e suas finalidades, integram 26 Fóruns que já foram instalados nos Estados e um no DF. A seguir tratar-se-á da pesquisa, objeto desse artigo. 


\section{A pesquisa: contexto, inquietações e tessitura do referencial teórico}

No Brasil, discutir o papel de um possível espaço de vivência democrática com composição plural, como se caracteriza o Profor, constitui uma ousadia, pois espaços como esse estáo inseridos na trama das políticas educacionais de um país que ainda permanece sob a égide da ideologia neoliberal, que aplica o modelo de Estado Mínimo que recrudesce as desigualdades educacionais, sociais e econômicas e destina recursos públicos para a iniciativa privada. No Estado brasileiro, o corolário da gestáo pública e privada recai no gerencialismo. Esse tipo de gestão invadiu a educaçáo básica e superior de tal modo que os critérios de empresariamento, a competitividade, a privatização, a individualização, a mercantilização, são adotados como fundamento de uma recente abordagem "[...] para as políticas públicas de educação [tendência que] está sendo construída em torno dos conceitos de responsabilização, meritocracia e privatização". (FREITAS, 2012, p. 346)

Ainda que hegemônicas nas políticas públicas em nosso país, as imposiçóes neoliberais são superadas em raros momentos históricos. Isso decorre de tensóes resultantes de certas conquistas do movimento contra hegemônico, materializado em manifestaçóes e açóes dos sujeitos sociais coletivos, na luta por um Estado que assuma a "democratização" da sociedade como valor universal. Essa expressão foi formulada por Lukács $(1987$, p. 25) que a prefere ao termo "democracia", pois para ele ontologicamente "democratização" é processo e não estado.

Perante o projeto neoliberal, os educadores que defendem a educaçáo pública, gratuita, laica, com qualidade social para todos os brasileiros em todos os níveis e modalidades, contrapóem-se à cultura da gestão gerencialista seguida pela educação do país. A intervenção do gerencialismo no campo da educação penetra as políticas de formação e valorização de professores, a dinâmica das instituiçóes formadoras, o projeto político pedagógico institucional, o papel social do professor, o trabalho docente, a aprendizagem e o desempenho discente.

Rummert, Algebaile e Ventura (2013, p. 718) esclarecem que o gerencialismo descarta o conhecimento como base fundamental da formação e propala que as questóes relativas à educação e à formação humana devem estar "predominantemente subsumidas ao capital". Salientam, também, que o modelo de gestâo gerencialista fundamenta-se, conceitualmente, no "capital-imperialismo". Conforme Fortes (2005, apud RUMMERT; ALGEBAILE; VENTURA, 2013, p. 718), esse capital caracteriza-se pelo: "predomínio do capital monetário"; "dominação da pura propriedade capitalista"; "impulso avassaladoramente expropriador". Nessa conjuntura, a educação é mercadoria, o que sugere que as políticas 
educacionais e a formação de profissionais da educação devam ser reguladas pelas leis de mercado, que rejeitam a formação omnilateral (voltar-se-á ao assunto), como marca essencial da docência.

As autoras alegam que as desigualdades socioeconômicas que penalizam cada vez mais a classe trabalhadora são associadas às educacionais e que a democracia no "capital-imperialismo" é reduzida a um modelo de atuação política de "padrão bifurcado": para o capital, o padrão é internacionalizado; para o trabalho é precarizado. A precarização e a expropriação conflitam-se com o direito constitucional de cidadania.

O padrão bifurcado é mais eficaz para a classe detentora dos meios de produção e de bens materiais por

[...] reduzir, ainda mais, os custos do trabalho, como, por exemplo, o empreendedorismo, o cooperativismo induzido, a terceirização, a quarteirização, a subcontratação, o trabalho domiciliar, ou seja, as diferentes estratégias de expropriação dos direitos do trabalho. (RUMMERT; ALGEBAILE; VENTURA, 2013, p. 719)

De acordo com Freitas (2012), as políticas educacionais, iluminadas pela "teoria da responsabilizaçấo", operam combinadas com o modelo gerencialista de gestão e o "padrão bifurcado". Sob essa padronização, o ethos da educação é mercadoria.

Emoldurado pelo "capital-imperialismo" e pelo gerencialismo emerge o modelo do "capitalismo trimestral". Consoante Gore (2013, p. 69-71), esse modelo se robustece e conduz à obsessão por projeçóes feitas a cada três meses, visando aos resultados e ao lucro a curto prazo. Nessa perspectiva, sáo utilizadas medições de desempenho por açóes e não por programas. Nela, as políticas de formação inicial e continuada de professores são tocadas por céleres açôes que o governo implementa e nas quais introduz um novo componente, que é

[...] constituído pelas ofertas educativas que propiciam possibilidades de acesso a diferentes níveis de certificação, falsamente apresentados como portadores de qualidade social igual à das certificaçōes às quais têm acesso as burguesias. Obscurece-se assim, cada vez mais, o fato de que não há, efetivamente, açōes destinadas à elevação igualitária do nível educacional da classe trabalhadora em sua totalidade. (RUMMERT; ALGEBAILE; VENTURA, 2013, p. 723) 
Os modelos supramencionados influenciam as políticas de formação de professores, pois advêm de questôes estruturais do capitalismo, e, assim, a educação destinada às classes trabalhadoras não se reveste de qualidade socialmente referenciada, como historicamente é assegurada à elite.

Os sujeitos sociais coletivos que lutam pela democratização da educação pública para todos os brasileiros estão do lado oposto das políticas governamentais aqui debatidas, nas quais a qualidade total determina que a formação de professores centre-se em competências operativas solicitadas de quem desenvolve um trabalho de execução, pouco qualificado cientificamente e que é sub-remunerado. São requeridas de um professor submetido às condiçôes indignas de trabalho, em forma de exploração incivilizatória e desumana.

Os sujeitos mencionados defendem um projeto de educaçáo e de formação de professores orientado por princípios sócio-históricos, de formação para o trabalho firmada em bases ontológicas, humanistas e praxiológicas. Essa formação é indispensável à construção de um professor capaz de ser mediador entre o conhecimento, a tecnologia, os saberes e o ser que aprende. Adeptos da pedagogia sócio-histórica, esses sujeitos reivindicam a formação omnilateral a ser oferecida por uma escola unitária, tal como preconizou Gramsci (2001), e foi assumida por Manacorda (2007) e Frigotto (2003). É escola de tempo integral, cuja práxis formativa deve promover o "[...] desenvolvimento de condiçôes físicas, mentais, afetivas, estéticas e lúdicas do ser humano, [e dessa forma é capaz] de ampliar a capacidade de trabalho na produçấo de valores e de seu uso em geral". (FRIGOTTO, 2003, p. 31)

As competências operativas foram propostas no corpus doutrinário das Diretrizes Curriculares Nacionais para a Formação Inicial de Professores para a Educação Básica, em Nivel Superior (BRASIL, 2002), como componente curricular "nucleador" das matrizes curriculares da Licenciatura. Os cursos emergenciais e os regulares de formação ministrados pelas IES seguem o que preceituam essas diretrizes.

\subsection{Organização dos cursos emergenciais presenciais: marcos regulatórios e o regime de colaboração}

No Brasil, a formação inicial do professor deveria realizar-se em cursos de primeira licenciatura, em nível superior. Nesse caso, o diploma de licenciado é condiçáo sine qua non para o postulante concorrer a uma vaga, mediante concurso de provas e títulos, a fim de exercer a profissão de professor e a atuar na educação básica pública. 
Causa estranhamento, todavia, que a legislação brasileira admita, no sistema público, normalistas formados em nível médio, como professores da educação infantil e dos cinco primeiros anos do ensino fundamental.

Esse ordenamento legal contrapóe-se à Anfope que, como sujeito social coletivo, desde 1983, reivindica que o ingresso no sistema público seja somente de professores formados em nível superior, em cursos oferecidos pela universidade, espaço de produção da ciência, do livre pensamento, da criatividade.

Quanto à formação continuada, Patrício (1991, p. 202) ressalta que ela requer desenvolvimento "profissional, cultural e social [...] e se confunde com a própria vida do professor". O autor adverte que, nesse processo formativo, deve ser estimulada, também, a autoformação, porém essa experiência depende de volição pessoal, que não é uma formaçáo individualista. A autoformação pode efetivar-se em espaços não formais de aprendizagem, mas sua qualidade é mais garantida, quando se realiza em atividades orientadas por um coletivo de docentes e pesquisadores que desenvolvem estudos, debates, reflexóes e diálogos acerca de questôes educacionais, científicas e pedagógicas.

Como faz parte do desenvolvimento profissional, a formação continuada deve ser assegurada pelo Estado mediante licença remunerada, tal como está previsto no inciso II, art. 67 da LDB/1996, o que é suficiente para justificar que se concilie um projeto institucional (prioritário) com o pessoal. Deve, também, ser estimulada por uma política da educação que responda às demandas educacionais da coletividade, traduzidas nos projetos políticos pedagógicos das escolas da educação básica, lócus privilegiado do trabalho docente.

No tocante à formação inicial e à continuada de professores realizadas em serviço, por meio de cursos emergenciais, a história recente da educação brasileira revela que a Política Nacional de Formação de Profissionais do Magistério da Educação Básica, editada em 2009, tem raízes em uma iniciativa malograda do MEC de criar de um Sistema Nacional Público de Formação de Profissionais do Magistério (2008). Tem suas bases, também, em um diagnóstico feito pela CAPES (2007) sobre a formação docente em nível superior no país. Esse diagnóstico constatou o crescimento da demanda pela educação básica pública e a falta de atratividade da profissão-professor.

O referido diagnóstico, os indicadores estatísticos e a estimativa para atender à demanda da educação, suscitada pela Emenda Constitucional n. 59/2009², indicaram que para ocupar 331.607 postos de trabalho, até 2014, seriam necessários professores formados em nível superior.

Diante desse quadro resultou o Decreto n. 6.755/2009, que prescreve a Política Nacional de Formação de Profissionais do Magistério da Educação a ser implementada 
[...] por meio da criação dos Fóruns Estaduais Permanentes de Apoio à Formação Docente, em regime de colaboração entre a União, os Estados, o Distrito Federal e os Municípios, e mediante açôes e programas específicos do Ministério da Educação. (BRASIL, 2009)

Tal como determina a Constituição Federal de 1988, $\$ 4^{\circ}$ do art. 211, o Decreto prevê que a Uniáo, os Estados, o DF e os Municípios definam formas de colaboração para assegurar a universalização do ensino obrigatório, conforme rege o art. $208, \$ 4^{\circ}$. (BRASIL, 1998)

No mesmo ano, foi emitida a Portaria Normativa n. 9, de 30/6/2009, prescrevendo o regime de cooperaçấo técnica entre a Capes, responsável direta pela gestáo das açôes do Parfor, e as Secretarias de Educação dos Estados e DF. Objetiva-se "[...] a mútua cooperaçáo técnico-operacional entre as partes, para organizar e promover a formação de professores das redes públicas de educação básica [...]". Articuladas as ações entre entes federativos, instituiçôes e órgãos de Estado, dever-se-ia, por força da lei, mapear as demandas reais para a formação inicial e continuada de professores.

A supracitada Portaria versa, ainda, a respeito da participaçáo das Instituiçôes Públicas de Educação Superior (IPES) a ser "formalizada por intermédio de Termo de Adesão aos respectivos Acordos de Cooperação, nos quais se estabelecerá a forma de implantação e execução dos cursos e programas do Plano Nacional de Formação de Professores". Faz, também, a previsão de 2 anos (2009-2011) para a entrada de professores/alunos nos cursos do Parfor.

Ainda em 2009, a Portaria Normativa n. 883, de 16/9, instituiu as diretrizes nacionais para o funcionamento dos Profor, especificando a natureza e as atribuições desses Fóruns vinculados às Secretarias de Educação.

A presente pesquisa constatou que o movimento de adesão dos Estados e do DF ao regime de colaboração foi instigado, em particular, pela prescrição no art. $4^{\circ} \$ 1^{\circ}$ do Decreto n. 6.755/2009, segundo o qual "[...] o regime de colaboração será concretizado por meio de planos estratégicos formulados pelos Fóruns [...] a serem instituídos em cada Estado e no Distrito Federal [...]".

As IPES aderiram como colaboradoras à política em favor da formação de professores leigos, e ofereceram vagas em cursos regulares e em turmas especiais, financiadas pela Capes/EB. Logo, a seguir, esse órgão possibilitou a adesão de instituiçóes comunitárias.

A Capes/EB organizou as planilhas de oferta de cursos e vagas por intermédio da Parfor, cujo ícone virtual materializou-se na Plataforma Paulo Freire. A mobilização da União, via MEC, motivou, em parte, os entes Estados e Municípios a instaurarem o regime de colaboraçấo no campo das políticas educacionais. 
É preciso lembrar que as ações do MEC centram-se em cursos de caráter emergencial, que visam corrigir distorçôes históricas, cujo enfrentamento tem implicaçōes políticas, disputa de poder, em face da autonomia relativa e às condicionalidades de cada ente federativo.

Cury (2011) adverte sobre o caráter de urgência de instaurar o regime de colaboração, em especial, por força da obrigatoriedade e gratuidade da educaçáo básica pública, proclamadas na EC n. 59/2009. Esse alerta remete aos determinantes da Federação, os quais encontram respaldo na CF/1988. Esta Carta Magna dá realce ao Estado democrático republicano. Este tem por princípio o

[...] sentido de igualdade como norte da própria república”, que instiga a projeção de açóes pactuadas para a educação e conclama a participação de todos com vistas ao bem comum. Propóe a organização da Federação [...] de tal forma que haja "um maior equilíbrio entre as regiōes e as unidades federativas. (CURY, 2013, p. 2)

A seguir, apresentar-se-ão os procedimentos que sustentaram o desenvolvimento da pesquisa em foco e também os resultados de sua primeira etapa.

\section{O movimento da pesquisa e a pesquisa em movimento}

Todo começo é difícil em qualquer ciência. (MARX, 1988, I, p. 4)

A abrangência da área de Ciências Humanas, em particular, do campo da Educação, é uma das causas do difícil começo para produzir ciência. (MARX, 1988) Esta característica suscita dilemas, contradiçóes e conciliaçóes impostas a qualquer pesquisador desse campo.

Os dilemas consistem em movimentos que encorajam indivíduos e sujeitos sociais coletivos a fazerem algo que demonstre ir além das possibilidades concretas de um espaço-tempo determinado.

A contradição é categoria essencial da dialética e está presente na realidade objetiva, fundamentada nas leis da unidade, na luta dos contrários, na totalidade. A contradição se manifesta pela reflexão sobre o movimento do real e a dinâmica interna dos elementos que são negados pelo seu contrário, negado e superado por novos elementos, em uma sequência de afirmação, negação e superação.

Conciliação, do latim conciliatio, etimologicamente significa "associação, união, benevolência, ação de procurar". Segundo o Dicionário eletrônico Houaiss (2009), conciliação é "ato de [...] porem-se de acordo litigantes, [em busca] de 
harmonizar pessoas desavindas ou discordantes”. Fernandes (1990, p. 144-145) é o aporte teórico que mais se aproxima da concepção de conciliação aqui adotada: a conciliação constitui um processo inevitável diante do dilema que se impôe na constituição de forças hegemônicas, que resolvem problemas educacionais conforme critérios "comerciais, confessionais ou inconfessáveis".

Passa-se, na sequência, ao movimento da pesquisa aqui enfocada, que tem por objetivo geral organizar um banco de informaçóes sobre o alunado dos cursos de formação inicial e continuada ministrados aos professores atuantes em escolas da educação básica. Busca-se identificar e analisar impactos do Parfor, com base nos planos estratégicos elaborados pelos Forprof, as Atas de suas reuniōes e a observação in loco, mediante pesquisa participante.

Os objetivos específicos da primeira etapa foram: a) organizar banco de dados da demanda, das necessidades de formação inicial e continuada, das vagas ofertadas e ocupadas por professores/cursistas; b) fazer uma comparação do desenvolvimento dos cursos de formação inicial e continuada presenciais, tendo como referência os planos estratégicos e o discurso presente nas Atas das reunióes dos Forprof; c) organizar um banco de dados do montante de recursos destinados ao financiamento desses cursos.

Este último objetivo não foi alcançado, embora tenham sido desprendidos esforços junto à União, aos Estados, ao Distrito Federal e à IES formadoras, pois enquanto durou o desenvolvimento da primeira etapa da pesquisa, esses dados não foram oficialmente divulgados. Eis uma grande contradição: executa-se o Parfor com acompanhamento das ações formativas de professores/alunos, porém não se publicam dados sobre os recursos aplicados. É lícito lembrar que eles advieram, em grande parte, de "empréstimos" internacionais.

O materialismo histórico dialético, como já citado, orienta a trajetória desta investigação qualitativa. Entende-se que a dialética instiga a pensar a realidade, o objeto em movimento, portanto, suscita tanto a ação de pensar os fatos como elementos de uma totalidade histórica quanto a submetê-los a uma análise crítica. Uma das dimensôes fundamentais desse método é o desenvolvimento histórico tratado como tempo descontínuo, como movimento.

$\mathrm{Na}$ pesquisa qualitativa, foram combinados procedimentos da pesquisa participante com análise documental e análise de dados, visando organizar um mapeamento de informaçóes em um banco de dados. De acordo com Barbier (2002), a pesquisa participante deve ser concebida como "ciência da práxis" e desenvolvida pelos investigadores in loco, "[...] num processo pessoal e único de reconstrução racional pelo ator social [...]".

Definiu-se uma amostra para a seleção dos dados empíricos. Os critérios para compô-la foram: a) existência de representante da Anfope nos Forprof; b) 
atendimento à diversidade regional brasileira; c) Forprof com status consolidado; d) Fórum em desenvolvimento; e) Fórum em fase embrionária de organização.

$\mathrm{Na}$ coleta de dados não foram poucas as dificuldades, em razão, sobretudo, da dinâmica de cada Forprof. Não se pode ignorar que alguns gestores estaduais e municipais, ao fazerem valer a prerrogativa de autonomia relativa de ente federado, legitimada pelo federalismo, interferem autoritariamente na organização e na dinâmica dos Fóruns, imprimindo sua ideologia e concepção de educação, de formação de professores e de desenvolvimento dos planos estratégicos. Tais posturas provocam desconforto nos sujeitos sociais coletivos, nos representantes das instituiçóes formadoras, entre outros, dispostos a garantir a "democratização" (LUKÁCS, 1987) do trabalho coletivo que deve ser construído como processo nos Forprof.

Outro procedimento metodológico escolhido foi a promoção de Encontros e Seminários Nacionais, Regionais e Estaduais, com o objetivo de sistematizar os dados e realizar análises das políticas estaduais, municipais e distrital de formação de professores implementadas pelos planos estratégicos dos Forprof.

\section{Revelações da pesquisa em movimento: alguns resultados e conclusões}

Marques (2002, p.11) afirma que o principal obstáculo ao federalismo brasileiro é o

[...] tensionamento entre autonomias, direitos e responsabilidades dos entes federativos, sem que se tenham fóruns de pactuação, em meio de discrepantes condiçóes econômicas e de gestão dos governos subnacionais. Embora a competência da oferta da educação básica obrigatória seja das três esferas administrativas (União, estados e municípios), as normas de relacionamentos e as condiçóes para o cumprimento das responsabilidades não estão bem definidas e refletem-se na ausência de um sistema nacional. Não há acordo federativo claro.

No caso do desenvolvimento do Parfor, embora não exista acordo federativo explícito, os entes federados foram impulsionados, pela demanda da sociedade por escolas públicas, a capacitarem professores aderindo ao Plano que promoveu a criação dos Forprof. Nesse sentido, esses Fóruns buscaram instaurar o regime de colaboração no campo das políticas de formação de professores, atribuindo-lhe conotação de relacionamento cooperativo, ainda que marcado por heterogeneidades e conflitos. Estes últimos, conforme se constatou pela pesquisa 
in loco, atém-se, sobremaneira aos determinantes da autonomia de cada ente federativo, à disputa de poder e às divergências político-partidárias.

No que tange aos resultados da investigação, o primeiro deles foi alcançado com a da análise documental de 234 Atas de reunióes realizadas nos 27 Fóruns, no período 2009-2014 e disponibilizadas no site da Capes/EB. Com essas análises foi possível reconhecer a importância dos Forprof para o desenvolvimento das políticas emergenciais de formação inicial e continuada de professores. Entre esses Fóruns, 14 (52\%) estão consolidados e podem ser visualizados na Figura 1.

\section{Figura 1}

FORPROF consolidados, por Região Geográfica e Estados-2014
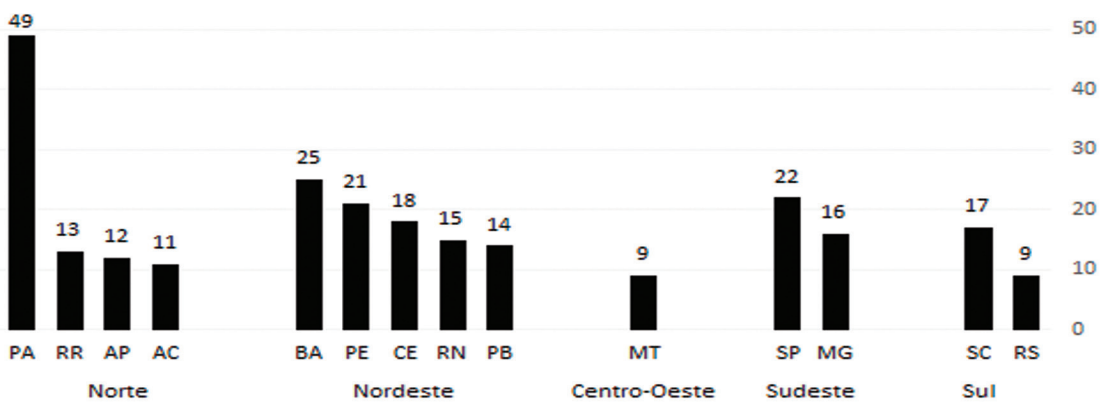

Fonte: Atas publicadas no site Capes/Parfor, 2013.

À época da primeira etapa da pesquisa, os Forprof em desenvolvimento somavam 11, abrangendo $41 \%$ do total e os em fase embrionária eram $2(7 \%)$, um estadual e um distrital. Os fóruns em desenvolvimento têm dificuldades para se reunirem sistematicamente, para cumprir o pacto federativo e, muitas vezes, não conseguem validar matrículas em tempo hábil na Plataforma Paulo Freire. Os fóruns em fase embrionária, embora instalados, não convocam os sujeitos sociais coletivos para reunióes, interrompem o diálogo entre a sociedade política e os representantes da sociedade civil, penalizando os professores que aspiram ao ingresso em um curso de licenciatura ou de formação pedagógica.

Entende-se que o índice de Forprof consolidados é um indicador de que eles poderão se transformar em espaços fecundos para o desenvolvimento do regime de colaboração, pois os Fóruns conseguiram, apesar de dificuldades, heterogenidades e conflitos, inserir os professores estaduais e municipais - sem curso superior - em cursos regulares ou em turmas especiais das universidades e institutos superiores, a maioria federais ou estaduais.

Um resultado preocupante é a constatação do elevado índice nacional de evasão dos professores/alunos, 69\%. As Figuras 2 e 3 trazem a comparação dos 
números absolutos de professores/alunos matriculados, desistentes e formados, referentes 2013, e aos cursos de primeira e segunda licenciatura.

\section{Figura 2}

Primeira Licenciatura: matriculados, formados e desistentes, 2013

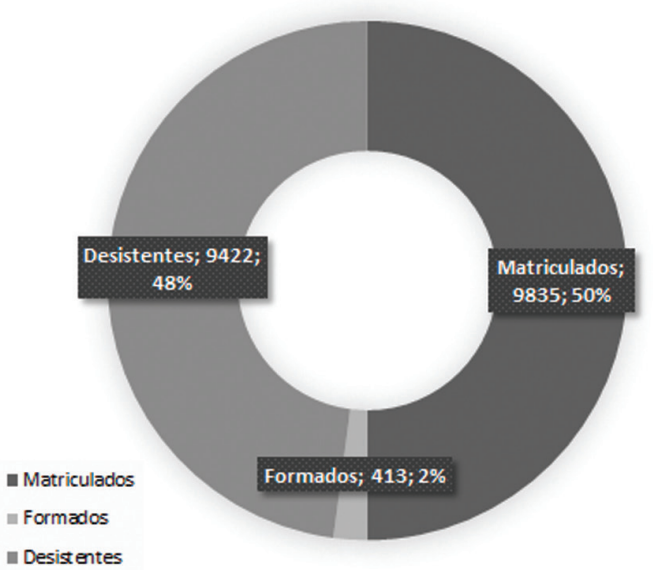

Fonte: CAPES/EB/Presencial 2014; BRZEZINSKI. Relatório de Pesquisa. CNPq 2013-2014.

\section{Figura 3}

Segunda Licenciatura: matriculados, formados e desistentes-2013

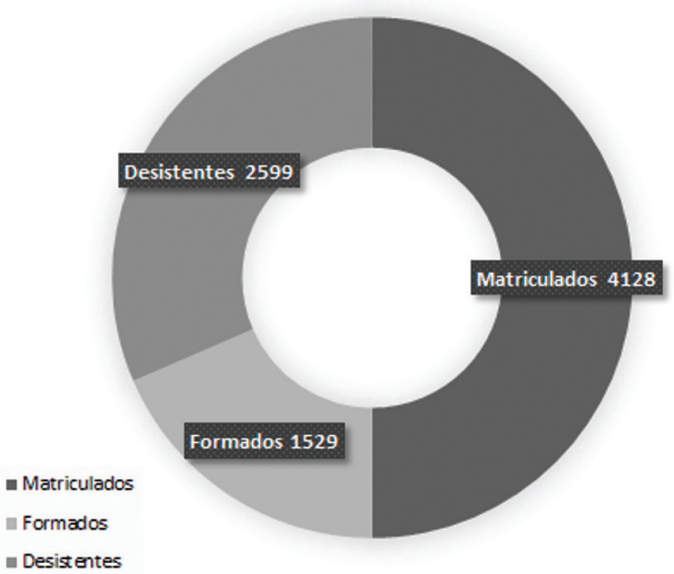

Fonte: CAPES/EB/Presencial 2014; BRZEZINSKI. Relatório de Pesquisa. CNPq 2013-2014. 
Além da oferta de cursos de primeira e segunda licenciatura, o Forprof oferece formação pedagógica a professores em exercício na educação básica. São contemplados docentes que náo são licenciados ou o são, mas atuam em área ou disciplinas alheias à sua formação. Analisando-se os números absolutos referentes aos professores que optam e fazem cursos de complementação de estudos, constata-se seu êxito quantitativo.

Os motivos desse sucesso são verbalizados pelos beneficiados: são cursos atrativos, pois têm curta duração (até um ano), possibilitam novas aprendizagens, permitem regularizar a situação funcional e abrem horizontes para o exercício da gestão escolar.

Dados acerca dos professores/alunos matriculados, formados e desistentes nos cursos de formação pedagógica são apresentados na Figura 4.

\section{Figura 4}

Formaçáo Pedagógica: matriculados, formados e desistentes-2013

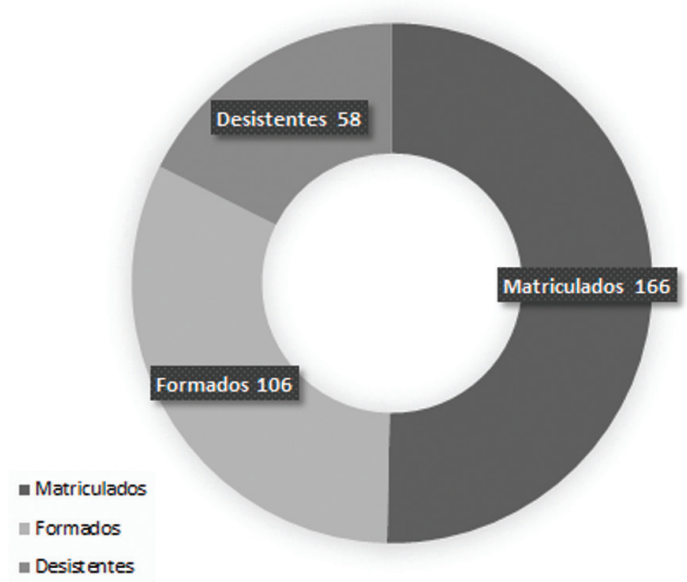

Fonte: CAPES/EB/Presencial 2014; BRZEZINSKI. Relatório de Pesquisa. CNPq 2013-2014.

Por meio da investigação em tela, verificou-se as principais causas do abandono pelos professores/alunos dos cursos oferecidos pelo Parfor . Eles não têm substitutos para ministrarem as suas aulas enquanto estudam. Além de não terem este direito atendido, são prejudicados, porque, quando resistem e continuam frequentes aos cursos são responsáveis pelo pagamento de quem se dispóe a substituí-los. Entretanto, alternativa de solução existe: o fortalecimento do regime de colaboração via relacionamento cooperativo entre os entes federados e suplementaçáo da Uniáo com programa de bolsa de estudos aos cursistas. 
Entre as constatações da pesquisa está o fato de que os Forprof têm configuraçôes muito diferenciadas e desenvolvimento desigual, em decorrência de disparidades locais (Municípios) e regionais (Estados).

Com a pesquisa participante observou-se que é preciso ter cautela ao utilizar as estatísticas oficiais da Capes/EB/Parfor e os dados reais. A título de exemplo, expóe-se a seguinte informação referente ao biênio 2010-2011, considerado o mais produtivo do Parfor. Os dados apurados revelam que 16.827 professores/cursistas fizeram matrícula nos campi de cinco instituiçóes superiores públicas, já os dados oficiais acusam somente 15.973 matriculados.

Concluída a primeira etapa da pesquisa ficou evidente a importância dos Fóruns Permanentes de Apoio à Formação Docente instalados em cada Unidade Federativa para o desenvolvimento da Política Nacional de Formação Inicial e Continuada dos Profissionais do Magistério. São indicadores dessa importância:

a) O Forprof, por força da legislação, é órgão colegiado, permanente e de composiçáo plural. Objetiva dar organicidade e realizar o controle social das políticas de formação e valorização dos profissionais da educação, em cada Estado da Federação e no DF. Com tais características, por questôes de coerência com o projeto sócio-histórico da educação, o Forprof precisa se declarar impedido de elaborar planos estratégicos de formação de professores, com base na ideologia do "capitalismo trimestral", da qual decorrem soluçóes apressadas e emergenciais. No campo da educação e das políticas de formação de professores não se viabiliza, em curto prazo, um processo formativo com qualidade socialmente referenciada.

b) Os fundamentos teóricos da formação de profissionais da educação devem manter nexos com o projeto sócio-histórico da educação, da formação de professores, da formação para o trabalho firmada em bases ontológicas, humanistas e praxiológicas. Para esse projeto, o ethos da educação é o conhecimento, educação não é mercadoria.

c) Existem possibilidades de o Forprof se fortalecer como espaço democrático e plural de mediação das políticas e processos de formação de professores. Desse modo, será garantida a participação na esfera pública aos sujeitos sociais coletivos, com vista a superar as prioridades governamentais que se voltam, muito mais, ao planejamento e execução de políticas pontuais, que não são políticas de Estado.

d) Esses Fóruns precisam transformar-se em mecanismos eficazes para levar a efeito a realização do regime de colaboração, via relacionamento cooperativo, ainda que marcados por heterogeneidades e conflitos. 
e) Os Forprof devem instigar a mobilização das instituições formadoras parceiras do Parfor presencial em serviço, para que ministrem cursos interiorizados, promovendo a socializaçáo de conhecimento, saberes, tecnologias e práticas formativas em locais que facilitem a concomitância de participação dos professores nos cursos e no trabalho docente.

A perspectiva é de que as parcerias firmadas entre os sujeitos sociais coletivos e os representantes da sociedade política, neste caso a Capes/EB e as Secretarias de Estado e Distrital da Educação, impulsionem a consolidação dos Fóruns Permanentes para que venham a constituir-se em embrião do Subsistema Nacional de Formação e Valorização dos Profissionais da Educação, articulado ao Sistema Nacional de Educação, pois sua regulamentação está em curso no Parlamento Brasileiro. Seria a superação do instável pelo dialeticamente instituinte!

\section{Notas}

1. Etimologicamente prótagónistês, ôu, significa aquele(es) que combate(m) na primeira fila.

2. Alterou, entre outros artigos da CF, o art. 208 e o art. 211. No Inciso I do art. 208 foi prescrita a obrigatoriedade e gratuidade da educação básica dos 4 (quatro) aos 17 (dezessete) anos de idade e a oferta gratuita para todos os que a ela náo tiveram acesso na idade própria. No $\$ 4^{\circ}$ do art. 211 consta a exigência de a União, os Estados, o Distrito Federal e os Municípios definirem formas de colaboração, com a finalidade de assegurar a universalização do ensino obrigatório regido pelo art. 208, $\$ 4^{\circ}$.

\section{Referências}

ALARCÃO, I. Desenvolvimento profissional, interação colaborativa e supervisão. Porto: Universidade Católica. Conferência proferida em 12/2/2004. Impresso.

BARBIER, R. A pesquisa-ação. Trad. de Lucie Didio. Brasília: Plano Editora, 2002.

BRASIL. Constituição (1988). Constituição da República Federativa do Brasil. Brasília, DF: Senado Federal, 1998.

. Lei n. 12.796, de 4/4/2013. Altera a Lei n. 9.394, de 20 de dezembro de1996, para dispor sobre a formação dos profissionais da educação e dá outras providências. Diário Oficial da República Federativa do Brasil. Brasília, DF, 5 abr. 2013.

. Lei n. 13.005, de 25/6/2014. Aprova o Plano Nacional de Educação - PNE e dá outras providências. Diário Oficial da República Federativa do Brasil. Brasília, DF, 26 jun.2014. Ediçẫo extra.

. Decreto n. 6.755, de 29/1/2009. Institui a política nacional de formaçấo de profissionais do magistério da educação básica, disciplina a atuação da coordenação de 
aperfeiçoamento de pessoal de nível superior. Diário Oficial da República Federativa do Brasil. Brasília, DF, 30 jan. 2009, p. 1.

BRASIL. Portaria Normativa n. 9, de 30/6/2009. Instituiu o Plano Nacional de Formação de Professores da Educação Básica. Diário Oficial da República Federativa do Brasil. Brasília, DF, 9 jul. 2009.

. Portaria Normativa n. 883, de 16/9/2009. Estabelece as diretrizes nacionais para o funcionamento dos Fóruns Estaduais Permanentes de Apoio à Formação Docente, criados pelo Decreto 6.755, de 29 de janeiro de 2009. Diário Oficial da República Federativa do Brasil. Brasília, DF, 17 set. 2009, p.26, Sessão 1.

. MEC. Plano Nacional de Formação dos Professores da Educação Básica. Disponível em htpp://www.mec.gov.br. Acesso em: 30 jun. 2013.

. MEC. Resolução CNE/CP n. 1, de 18/2/2002. Institui as Diretrizes Curriculares Nacionais para a Formação Inicial de Professores para a Educação Básica em Nível Superior, Curso de Licenciatura, de graduação plena. Disponível em http://portal.mec.gov.br/ cne/arquivos/pdf/rcp01_02.pdf. Acesso em: 10 jan. 2014.

. Emenda constitucional no 59 de 11/11/2009. Acrescenta $₫ 3^{\circ}$ ao art. 76 do Ato das Disposiçóes Constitucionais Transitórias para reduzir, anualmente, a partir do exercício de 2009, o percentual da Desvinculação das Receitas da União incidente sobre os recursos destinados à manutenção e desenvolvimento do ensino. Diário Oficial da República Federativa do Brasil. Brasília, DF, 12 dez. 2009.

BRZEZINSKI, I. Fóruns Permanentes de Apoio à Formação Docente: espaço democrático mediador de politicas de formação de professores e do regime de colaboração? Disponível em http://www.anpae.org.br/simposio26/1comunicacoes/IriaBrzezinski-ComunicacaoOral-int.pdf. Acesso em: 10 fev. 2013.

COUTINHO, C. N. Contra a corrente: ensaios sobre democracia e socialismo. 2. ed. revista. São Paulo: Cortez, 2008.

CURY, C. R. J. Por um novo plano nacional de educação. Cadernos de Pesquisa, São Paulo, v. 41, n. 144, p. 790-811, set./dez. 2011.

. Os conteúdos mínimos curriculares e a educação nacional. Belo Horizonte, 2013. Impresso.

DOURADO, L. F. Federalismo, educação e a construção de políticas de Estado. Editorial Revista Retratos da Escola, Brasília, v. 6, n. 10, p. 7-9/Contracapa, jan./jun. 2012

FERNANDES, F. Diretrizes e bases: conciliação aberta. Educação \& Sociedade, Campinas, ano XI, n. 36, ago. 1990, p. 142-149.

FREITAS, L. C. Apresentação: Políticas públicas de responsabilização na educação. Educação \& Sociedade, Campinas, v. 33, n. 119, p. 345-349, abr/jun. 2012.

FRIGOTTO, G. O enfoque da dialética materialista histórica na pesquisa educacional. In: FAZENDA, I. (Org.). Metodologia da pesquisa educacional. São Paulo: Cortez, 1997. . Educação e a crise do capitalismo real. 5 ed. São Paulo: Cortez, 2003. 
GRAMSCI. A. Cadernos do cárcere. Os intelectuais. O princípio educativo. Jornalismo. Rio de Janeiro: Civilização Brasileira, 2001. vol. 2.

GOHN, M. da G. Empoderamento e participação da comunidade em políticas sociais. Saúde e Sociedade, v.13, n. 2, p.20-31, maio/ago. 2004

GORE, A. O futuro: seis forças que irão mudar o mundo. Trad. Jaime Araújo. Lisboa: Conjuctura Atual, 2013.

HOUAISS, A. Dicionário eletrônico da língua portuguesa. Rio de Janeiro: Instituto Antônio Houaiss/Objetiva, 2009.

LUKÁCS, G. L’uomo e la democrazia. Roma: Lucarini, 1987.

MANACORDA, M. A. Marx e a pedagogia moderna. Campinas: Alínea, 2007.

MARQUES, A. Federalismo e educação: novos marcos e perspectivas. Entrevista concedida a Luiz Fernandes Dourado. Retratos da Escola, v.6, n. 10, p, 11-19, jan./jul. 2012.

MARX, K. O capital: crítica da economia política. 12 ed. Trad. R. Sant'Ana. Rio de Janeiro: Bertrand do Brasil, 1988.

MARX, K.; ENGELS, F. Manifesto do Partido Comunista. Disponível em htp//:www. culturabrasil.pro.br/manifestocomunista. Acesso em: 8 set. 2014. (1ª edição, 1848).

- A ideologia alemã: crítica da mais recente filosofia alemã em seus representantes

Feuerbach, B. Bauer e Stirner, e do socialismo alemão em seus diferentes profetas (18451846). Trad. R. Enderle; N. Scheneider, L. C. Martorano. São Paulo: Boitempo, 2007. (1 a edição, 1933).

PATRÍCIO. M. F. Por que uma dimensão histórico-cultural na formação contínua de professores? In: TAVARES, J. (Org.). Formaçâo contínua de professores: realidade e perspectivas. Portugal: Universidade de Aveiro, 1991, p.199-202.

RUMMERT, S. M.; ALGEBAILE, E.; VENTURA, J. Educação da classe trabalhadora brasileira: expressão de desenvolvimento desigual e combinado. Revista Brasileira de Educação, v. 18, n.54, p. 717-738, jul./set. 2013.

Recebido em 02 de dezembro de 2014. Aprovado em 27 de fevereiro de 2015. 